\title{
ANALISIS FAKTOR-FAKTOR YANG MEMPENGARUHI KECELAKAAN KERJA PERAWAT DALAM PELAYANAN KESEHATAN/KEPERAWATAN DI RUMAH SAKIT
}

\author{
Tri Anjaswarni ${ }^{1)}$, Susi Milwati ${ }^{2)}$, Karliyn Ayu Angelina Marpaung ${ }^{3)}$ \\ 1, 2, ${ }^{3}$ Poltekkes Kemenkes Malang \\ e-mail: tri_anjaswarni@poltekkes-malang.ac.id
}

\begin{abstract}
ABSTRAK
Kecelakaan kerja bisa terjadi di tempat kerja yang memiliki bahaya potensial tinggi. Kecelakaan kerja di Rumah sakit dapat menggangu produktivitas dan kualitas kerja perawat dalam melakukan asuhan keperawatan. Mengetahui faktor-faktor yang mempengaruhi kecelakaan kerja perawat di Rumah sakit adalah penting, agar dapat dilakukan tindakan pencegahan. Metode penelitian adalah Literature review, dengan menggunakan data sekunder dari penelitian terdahulu dari database PubMed, Science Direct, Google Schoolar. Literatur yang dipilih, menggunakan desain cross sectional, terbit pada tahun 2015-2020, artikel dipilih sesuai kriteria.Artikel diseleksi menggunakan diagram PRISMA. Terdapat sepuluh jurnal yang direview dan dianalisis. Penilaian kualitas dari sepuluh artikel yang dipilih, dilakukan dengan menggunakan The Joanna Briggs Institute (JBI) Critical Appraisal.Hasilreview dan analisis didapatkan bahwa faktor yang mempengaruhi kecelakaan kerja perawat di Rumah sakit ada empat, yaitu pengawasan, pelatihan, shift kerja perawat dan safety attitude. Pengawasan yang teratur, peningkatan kompetensi melalui pelatihan, dan safety attitude adalah faktor yang penting diperhatikan agar dapat mencegahkecelakaan kerja. Perawat yang bekerja shift pagi dan malam perlu mendapatkan istirahat yang cukup karena akibat kerja shift, mereka lebih sering mengalami kecelakaan kerja karena beban tugas yang berat dan waktu kerja yang lama.
\end{abstract}

Kata Kunci: faktor-faktor; kecelakaan kerja; perawat

\section{ABSTRACT:}

Work accidents can occur in a workplace that has a high potential hazard. Work accidents in hospitals can interfere with the productivity and quality of work of nurses in performing nursing care.Knowing the factors that affect nurses' work accidents in hospitals is important, so that preventive measures can be taken.The research method was Literature review, using secondary data from previous research from the database of PubMed, Science Direct, Google Scholars.The selected literature, using a cross sectional design, was published in 2015-2020. Journals were selected using the PRISMA diagram. There are ten journals that are reviewed and analyzed. The quality assessment of the ten selected articles was carried out using The Joanna Briggs Institute (JBI) Critical Appraisal. Based on the results of the review and analysis, it was found that the factors that affect nurses' work accidents in hospitals are supervision, training, nurse work shifts and safety attitude. Regular supervision, competency improvement through training, and safety attitude are important factors to be considered in order to prevent work accidents. Nurses who work morning and night shifts need to get adequate rest because due to shift work, they are more likely to have work accidents due to their heavy workload and long working hours.

Keywords: factors; nurse; occupational accident 


\section{PENDAHULUAN}

Kecelakaan kerja adalah kejadian yang tidak terencana yang menyebabkan cidera, kesakitan atau kerusakan yang terjadi di tempat kerja. Kecelakaan kerja biasanya terjadi di tempat kerja yang memiliki bahaya potensial tinggi. Hasil penelitian di banyak negara, menunjukkan bahwa dunia kerja perawatan dan kesehatan, memiliki tingkat kecelakaan, cidera, dan penyakit yang jauh lebih tinggi jika dibandingkan dengan dunia industri lainnya (Aslam et al. 2015). Kecelakaan kerja di rumah sakit, dapat mempengaruhi produktivitas kerja perawat dan profesional kesehatan lainnya (Marbun 2020).

Lingkungan rumah sakit, merupakan tempat yang dapat berpotensi tinggi menimbulkan kecelakan kerja. Berbagai faktor di lingkungan rumah sakit yang berpotensi bahaya, antara lain faktor fisik, biologi, kimia, ergonomik, dan faktor psikososial (Kepmenkes 2010).

(Mccaughey et al. (2016) mengidentifikasi empat faktor yang mempengaruhi kecelakaan kerja di rumah sakit ditinjau dari petugas kesehatan, yaitu karakteristik individu, kerja shift, program keselamatan, dan pelatihan. Kerja shift rumah sakit adalah faktor yang berrisiko tinggi mengakibatkan cidera di antara perawat (Bae and Fabry 2014).

Sebagian besar perawat mengalami kondisi yang sulit, karena mereka harus tetap mempertahankan kinerja pelayanan dan asuhan keperawatan secara optimal dalam waktu 24 jam sehari, yang terbagi dalam shift dinas. Beberapa risiko kecelakaan kerja perawat adalah kondisi fisik yang kurang prima, kelelahan mental, kekurangan tenaga, beban kerja berlebihan, kerja shift, shift malam, dan lembur (Caruso 2015). Kondisi yang dialami perawat tersebut dapat menjadi masalah dan meningkatkan potensi kecelakaan kerja perawat
(Davas, Türk, and Yüksek 2016).

Kejadian kecelakaan kerja di Rumah Sakit terjadi di beberapa negera. Di Amerika dilaporkan bahwa pada tahun 2013, kasus kecelakaan kerja di Rumah sakit tercatat 244.800 kejadian kecelakaan dan penyakit dengan rate sebesar 6.4 per 100 jam kerja (OSHA 2015). Penelitian di negara berkembang antara lain di India, dilaporkan bahwa dalam 1 tahun terakhir terdapat 5,4\% perawat mengalami luka akibat tertusuk jarum suntik, 7,4\% mengalami varises, dan $56,9 \%$ mengalami stres kerja (Nayak et al. 2016). Di Indonesia terdapat beberapa kasus kecelakaan kerja, antara lain tahun 2015 di Rumah Sakit Umum Daerah dr. Zainoel Abidin Banda Aceh terjadi 19 kasus kecelakaan kerja dimana 18 kasus diantaranya terjadi pada perawat (Nazirah and Yuswardi 2017). Di Instalasi Bedah Sentral RSUD Dr Iskak Tulungagung dilaporkan pada periode 25 Mei sampai 15 Juni 2017, dari 34 perawat instrument, didapatkan 29 orang diantaranya $\quad(85,29 \%) \quad$ pernah mengalami cidera (Pitoyo et al. 2017). Kecelakaan kerja dapat memengaruhi produktivitas dan kinerja perawat. Kecelakaan kerja di rumah sakit adalah masalah serius karena mengancam kesehatan dan kesejahteraan pasien dan petugas kesehatan (Maria, Wiyono, and Candrawati 2015).

Berdasarkan permasalahan di atas, maka perlu mengetahui faktor risiko yang dapat mempengaruhi kecelakaan kerja, sehingga dapat dilakukan tindakan korektif, dan upaya preventif dengan tujuan mencegah kecelakaan, dan tidak berulang terjadi (Suma'mur 2013).Tujuan studi literatur ini adalah mengetahui faktor-faktor yang mempengaruhi kecelakaan kerja perawat dalam memberikan pelayanan keperawatan dan kesehatan di rumah sakit. 


\section{METODE PENELITIAN}

Metode penelitian adalah studi literatur atau literature review. Literatur review merupakan ikhtisar komprehensif tentang penelitian yang sudah dilakukan oleh peneliti sebelumnya terkait topik spesifik untuk menunjukkan kepada pembaca apa yang sudah diketahui dan apa yang belum diketahui. Studi dilakukan untuk mencari rasional dari penelitian yang sudah dilakukan atau untuk menemukan ide penelitian selanjutnya (Denney and Tewksbury, 2015).

Strategi yang digunakan dalam pencarian literature ada tiga metode, yaitu1) protokol dan registrasi, 2) database pencarian, dan 3) kata kunci.

Protokol dan registrasi merupakan rangkuman yang ditulis secara menyeluruh dari hasil studi literature terkait faktor-faktor yang mempengaruhi kecelakaan kerja perawat dalam memberikan pelayanan kesehatan/ keperawatan di Rumah sakit. Protokol dan evaluasi dilakukan dengan menggunakan PRISMA checklist untuk penyeleksian literaturyang ditemukan dan disesuaikan dengan tujuan (Nursalam 2020).

Pencarian literatur dariDatabase, dilakukanpada bulan Oktober Desember 2020. Jenis data adalah data sekunder yang diperoleh dari peneliti terdahulu. Sumber data berupa artikel jurnal bereputasi, baik nasional maupun internasional sesuai dengan tema dan tujuan studi. Pencarian literature menggunakan tiga database dengan kriteria kualitas tinggi dan sedang, yaitu Pubmed, Science Direct, dan Google Scholar.

Kata Kunci pencarian artikel atau jurnal, menggunakan keyword dan boolean operator (AND, OR NOT or $A N D$ NOT) untuk memperluas atau menspesifikkan pencarian jurnal, sehingga mempermudah dalam penentuan artikel. Kata kunci dalam literature review ini disesuaikan dengan Medical Subject Heading (MeSH)
(Nursalam dan Hons, 2020).

Strategi selanjutnya yang digunakan untuk mencari artikel, dilakukan dengan menetapkan kriteria inklusi dan eklusi menggunakan kerangka PEOS (Population, Exposure, Outcomes dan Study Design). Population, adalah semua artikel terkait tema yang ditetapkan dan akan dianalisis, yaitu faktor-faktor yang mempengaruhi kecelakaan kerja pada perawat di Rumah sakit. Exposure yaitu faktor kecelakaan kerja perawat. Outcomes yaitu luaran dari studi yang dilakukan dari artikel yang direview, yaitu faktor yang mempengaruhi atau berhubungan dengan kecelakaan kerja perawat. Study design, yaitu desain penelitian dari artikel yang dipilih. Disain yang dipilih dari artikel yang digunakan adalah cross sectional dengan analisis korelasional. Time adalah periode waktu penerbitan artikel yang digunakan, yaitu tahun 2015-2020, menggunakan bahasa indonesia dan bahasa inggris.

Berdasarkan hasil pencarian literature di tiga database pada bulan Oktober sampai Desember tahun 2020 diperoleh 289 artikel yang sesuai dengan kriteria, dengan perincian sebagai berikut: dari PubMed ( $\mathrm{n}=130)$, Science Direct $(\mathrm{n}=77)$, dan Google Scholar $(\mathrm{n}=82)$. Hasil pencarian yang didapatkan, selanjutnya diperiksa kemiripan atau duplikasi. Didapatkan 77 artikel yang sama sehingga dikeluarkan dan didapatkan 212 artikel.

Artikel yang diperoleh, selanjutnya dilakukan skrining. Berdasarkan hasil skrining didapatkan bahwa artikel yang sesuai dengan kriteria sejumlah $\mathrm{n}=212$ artikel, berdasarkan abstrak didapatkan yang sesuai kriteria sejumlah $n=44$ artikel dan secara full text didapatkan sesuai kriteria sejumlah $\mathrm{n}=10$ artikel (seperti pada gambar 1).

Dari sepuluh artikel yang diperoleh, selanjutnya dilakukan penilaian kualitas dengan menggunakan Check-lyst The Joanna Briggs Institute (JBI) Critical Appraisal. Jurnal atau artikel dinilai berkualitas jika Skor yang diperoleh 
lebih dari 50\%. Dari sepuluh artikel yang dinilai kualitasnya, semua mempunyaikualifikasi baik dengan skor lebih dari 50\%, dengan rata-rata presentase $76,25 \%$, sehingga untuk selanjutnya siap dilakukan review dan analisis.
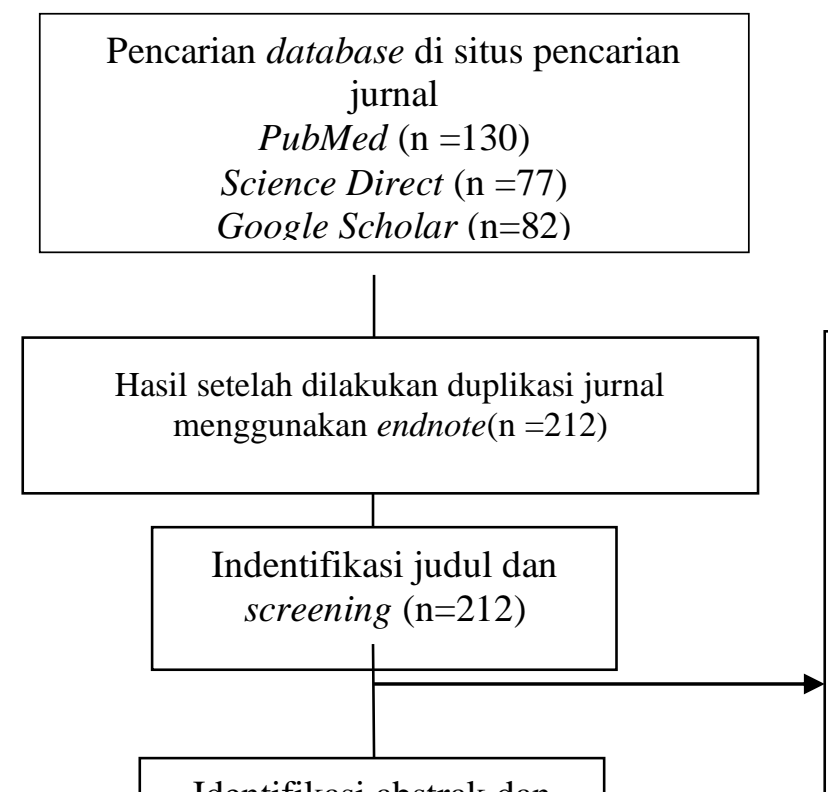

Exluceded $(\mathrm{n}=168)$

Participant

Tidak fokus pada perawat $(n=42)$

Exposure

Tidak relevan faktor kecelakaan

kerja perawat $(\mathrm{n}=53)$

Outcomes

Tidak membahas faktor yang mempengaruhi/ berhubungan dengan kecelakaan kerja perawat

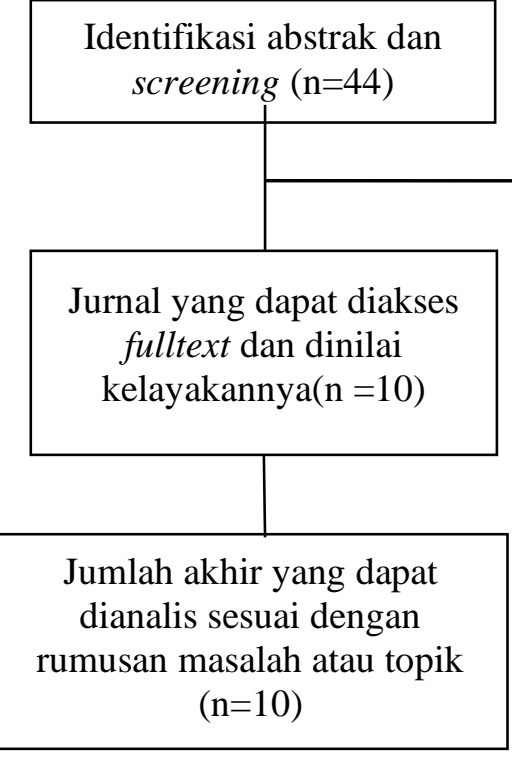

Exluceded $(\mathrm{n}=34)$

\section{Participant}

Tidak fokus pada perawat $(\mathrm{n}=11)$

Exposure

Tidak relevan dengan faktor kecelakaan kerja perawat $(\mathrm{n}=8)$

\section{Outcomes}

Tidak membahas faktor yang mempengaruhi/ berhubungan dengan kecelakaan kerja perawat 
bersumber dari tiga data data based, dengan perincian tujuh jurnal internasional dan 3 jurnal nasional. Tujuh jurnal internasional merupakan studi yang dilakukan di Amerika Serikat, Ethiopia, Iran, Turki, Trinidad, dan Brazil. Tiga jurnal nasional merupakan studi yang dilakukan di
Medan, Palu, dan Pekanbaru.Berdasarkan tahun terbitan jurnal / artikel didapatkan tahun 2015 (2artikel), 2018 (2artikel), 2019 (5artikel), dan tahun 2020 (1artikel).Ringkasan hasil review literatur seperti tabel 1. 
Tabel 1 Hasil Studi LiteraturFaktor-Faktor Yang Mempengaruhi Kecelakaan Kerja PerawatDalam Pelayanan Kesehatan / Keperawatan Di Rumah Sakit

\begin{tabular}{|c|c|c|c|}
\hline Judul, Penulis & $\begin{array}{l}\text { Jurnal, } \\
\text { Tahun }\end{array}$ & $\begin{array}{l}\text { Desain studi, sampel, } \\
\text { variabel, instrument, } \\
\text { analisis }\end{array}$ & Hasil \\
\hline $\begin{array}{l}\text { Safety Attitudes } \\
\text { among Nurses and } \\
\text { Its Relation with } \\
\text { Occupational } \\
\text { Accidents: A } \\
\text { Questionnaire } \\
\text { BasedSurvey(Samaei } \\
\text { et al., 2015). }\end{array}$ & $\begin{array}{l}\text { International } \\
\text { Journal of } \\
\text { Occupational } \\
\text { Hygiene } \\
\text { Volume } 7 \text {, } \\
\text { Nomor } 4 \text {, } \\
\text { tahun } 2015\end{array}$ & $\begin{array}{l}\text { Desain :Cross sectional } \\
\text { study, Sampel : } 244 \\
\text { perawat, Variabel } \\
\text { :Safety Attitudes, } \\
\text { kecelakaan kerja, } \\
\text { Analisis :Pearson } \\
\text { correlation, } \\
\text { independent t-test and } \\
\text { ANOVA. }\end{array}$ & $\begin{array}{l}\text { Terdapat hubungan paparan darah atau } \\
\text { cairan tubuh dan trauma punggung } \\
\text { dengan safety attitude }(\mathrm{P}<0.05) \text {. }\end{array}$ \\
\hline $\begin{array}{l}\text { Scheduling and shift } \\
\text { work characteristics } \\
\text { associated with risk } \\
\text { for occupational } \\
\text { injury in newly } \\
\text { licensed registered } \\
\text { nurses: An } \\
\text { observational } \\
\text { study(Witkoski et } \\
\text { al., 2015). }\end{array}$ & $\begin{array}{l}\text { International } \\
\text { Journal of } \\
\text { Nursing } \\
\text { Studies, } \\
\text { volume } 52 \\
\text { nomor } 11, \\
\text { tahun } 2015 \text {. }\end{array}$ & $\begin{array}{l}\text { Desain :Cross sectional } \\
\text { study, Sampel : } 1722 \\
\text { perawat baru, Variabel } \\
\text { : } \\
\text { shift, kecelakaan kerja, } \\
\text { Analisis :regresi linier }\end{array}$ & $\begin{array}{l}\text { Terdapat hubungan perawat yang } \\
\text { bekerja shift malam dengan kejadian } \\
\text { keseleo dan cidera otot }\end{array}$ \\
\hline $\begin{array}{l}\text { Pelaksanaan } \\
\text { keselamatan dan } \\
\text { kesehatan kerja } \\
\text { terhadap kejadian } \\
\text { kecelakaan kerja } \\
\text { perawat rumah sakit } \\
\text { (Putri \& Rahayu, } \\
\text { 2018a). }\end{array}$ & $\begin{array}{l}\text { Jurnal } \\
\text { Endurance } \\
\text { volume } 3 \text {, } \\
\text { nomor 2, } \\
\text { tahun 2018 }\end{array}$ & $\begin{array}{l}\text { Desain :Cross } \\
\text { sectional study, } \\
\text { Sampel : } 164 \text { perawat } \\
\text { baru, Variabel : Sikap, } \\
\text { pelatihan, pengawasan, } \\
\text { kejadian kecelakaan } \\
\text { kerja, Analisis: Uji chi } \\
\text { square,, regresi logistik } \\
\text { ganda }\end{array}$ & 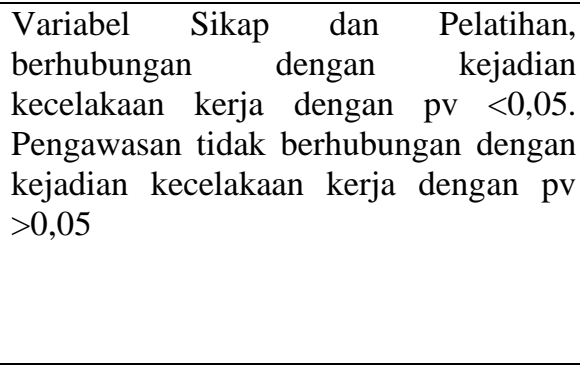 \\
\hline $\begin{array}{l}\text { Prevalence of } \\
\text { Needle-stick and } \\
\text { Sharp Object } \\
\text { Injuries and its } \\
\text { Associated Factors } \\
\text { among Staff Nurses } \\
\text { in Dessie referral } \\
\text { Hospital Amhara } \\
\text { Region, Ethiopia, } \\
\text { 2018 (Abebe et al., } \\
\text { 2018). }\end{array}$ & $\begin{array}{l}\text { BMC } \\
\text { Research } \\
\text { Notes } \\
\text { volume } 11 \\
\text { nomor } 1 \text {, } \\
\text { tahun } 2018 \text {. }\end{array}$ & $\begin{array}{l}\text { Desain : Cross } \\
\text { sectional study, } \\
\text { Sampel : } 256151 \\
\text { perawat, Variabel } \\
\text { :Pelatihan, work area, } \\
\text { kecelakaan } \\
\text { kerja,Analisis: } \\
\text { Bivariabel dan } \\
\text { multivariabel dengan } \\
\text { analisis ujiregresi } \\
\text { logistik }\end{array}$ & $\begin{array}{l}\text { - Perawat yang bekerja di unit } \\
\text { gawat darurat11x berisiko } \\
\text { mengalami tusukan jarum dan } \\
\text { cidera benda tajam dibandingkan } \\
\text { dengan perawat yang bekerja di } \\
\text { departemen rawat jalan dengan pv } \\
=0,004(<0,05) \text {. } \\
\text { - } \quad \text { perawat di rawat inap 10x } \\
\text { berisiko mengalami luka tusuk } \\
\text { jarum dan benda tajam jika } \\
\text { dibandingkan dengan perawat di } \\
\text { rawat jalan dengan pv =0,006. } \\
\text { Perawat yang pernah } \\
\text { mengikuti pelatihan, mengalami } \\
\text { tusuk jarum dan benda tajam } 4 \mathrm{x} \\
\text { lebih kecil dibandingkan dengan } \\
\text { yang tidak ikut pelatihan dengan Pv } \\
=0,021(<0,05) \text { Perawat yang tidak } \\
\text { - } \\
\text { menerapkan kewaspadaan universal } \\
\text { 6x lebih mungkin mengalami cidera } \\
\text { tertusuk jarum dan benda tajam }\end{array}$ \\
\hline
\end{tabular}




\begin{tabular}{|c|c|c|c|}
\hline & & & $\begin{array}{l}\text { dibandingkan dengan yang } \\
\text { menerapkan dengan } \mathrm{pv}=0,001\end{array}$ \\
\hline $\begin{array}{l}\text { Factors Affecting } \\
\text { The Occupational } \\
\text { Accident Rates } \\
\text { Among Nurses } \\
\text { (Dilek, 2019). }\end{array}$ & $\begin{array}{l}\text { Journal of } \\
\text { School of } \\
\text { Nursing } \\
\text { volume } 53 \text {, } \\
\text { nomor } 1 \text {, } \\
\text { tahun } 2019\end{array}$ & $\begin{array}{l}\text { Desain :cross sectional } \\
\text { study, Sampel : } 108 \\
\text { perawat, Variabel } \\
\text { :Jenis kelamin, umur, } \\
\text { masa kerja, shift, } \\
\text { kecelakaan kerja, } \\
\text { Analisis :Chi- } \\
\text { squareTest,Independent } \\
\text { Samples T-Test, } \\
\text { Kruskal-Wallis Test. }\end{array}$ & 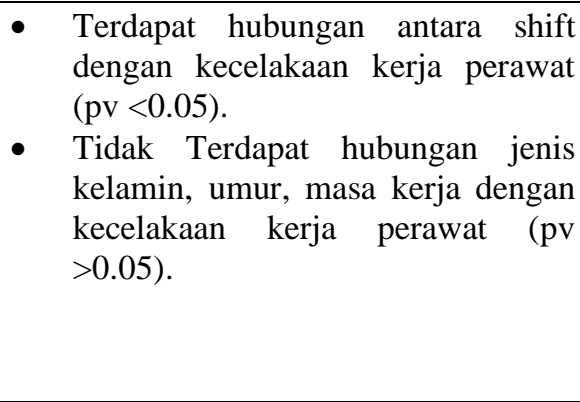 \\
\hline $\begin{array}{l}\text { Factors Affecting } \\
\text { Occupational } \\
\text { Hazards among } \\
\text { Operating Room } \\
\text { Personnel at } \\
\text { Hospitals } \\
\text { Affiliatedin in } \\
\text { Western Iran: A } \\
\text { Cross-Sectional } \\
\text { Study (Lebni et al., } \\
\text { 2019). }\end{array}$ & $\begin{array}{l}\text { Journal of } \\
\text { Public } \\
\text { Health: } \\
\text { From Theory } \\
\text { to Practice, } \\
\text { Tahun } 2019\end{array}$ & $\begin{array}{l}\text { Desain : Cross } \\
\text { sectional study, } \\
\text { Sampel : } 450 \text { perawat } \\
\text { kamar operasi, } \\
\text { Variabel :Umur, jenis } \\
\text { kelamin, pendidikan, } \\
\text { masa kerja, shift, } \\
\text { bahaya kecelakaan } \\
\text { kerja, Analisis } \\
\text { :ANOVA dan } \\
\text { independent } t \text {-test }\end{array}$ & $\begin{array}{l}\text { Umur, jenis kelamin, pendidikan, masa } \\
\text { kerja berhubungan dengan kecelakaan } \\
\text { kerja ( }<<0.05) \text {. sedangkan shift tidak } \\
\text { berhubungan dengan kecelakaan kerja } \\
(p>0.05)\end{array}$ \\
\hline $\begin{array}{l}\text { Faktor yang } \\
\text { Berhubungan } \\
\text { dengan Kejadian } \\
\text { Kecelakaan Kerja } \\
\text { pada Perawat di } \\
\text { Ruang IGD RSU } \\
\text { Anutapura Kota Palu } \\
\text { (Salmawati, Rasul, } \\
\text { et al., 2019). }\end{array}$ & $\begin{array}{l}\text { Jurnal } \\
\text { Kesehatan } \\
\text { Masyarakat } \\
\text { volume 10, } \\
\text { nomor 2, } \\
\text { tahun 2019), } \\
104-112\end{array}$ & $\begin{array}{l}\text { Desain : Cross } \\
\text { sectional study, } \\
\text { Sampel : } 31 \text { perawat di } \\
\text { Ruang IGD } \\
\text { RSUAnutapura Kota } \\
\text { Palu, Variabel : Umur, } \\
\text { jenis kelamin, masa } \\
\text { kerja, penggunaan } \\
\text { APD, pelatihan K3, } \\
\text { Pengawasan, } \\
\text { Kecelakaan } \\
\text { Kerja,Analisis : Uji Chi } \\
\text { Square }\end{array}$ & $\begin{array}{l}\text { Hasil penelitian ada hubungan umur } \\
(\mathrm{p}=0,002) \text {, jenis kelamin }(\mathrm{p}=0,019), \\
\text { penggunaan APD }(\mathrm{p}=0,007) \text {, pelatihan } \\
(\mathrm{p}=0,007) \text {, pengawasan }(\mathrm{p}=0,006) \\
\text { dengan kecelakaan kerja. Tidak ada } \\
\text { hubungan masa kerja dengan } \\
\text { Kecelakaan Kerja }(\mathrm{p}=0,083)\end{array}$ \\
\hline $\begin{array}{l}\text { Factors Related to } \\
\text { Occupational } \\
\text { Accidents Among } \\
\text { Nursing } \\
\text { Professionals from a } \\
\text { Public Hospital in } \\
\text { Northern Brazil } \\
\text { between the Years } \\
2009 \text { to } \\
\text { 2016(Peixoto et al., } \\
\text { 2019). }\end{array}$ & $\begin{array}{l}\text { Journal } \\
\text { Revista } \\
\text { Brasileira De } \\
\text { Medicina Do } \\
\text { Trabalho } \\
\text { volume } 17, \\
\text { nomor4, } \\
\text { tahun 2019), } \\
521-529\end{array}$ & $\begin{array}{l}\text { Desain : Cross } \\
\text { sectional study, } \\
\text { Sampel : } 211 \text { perawat, } \\
\text { Variabel : Shift dinas, } \\
\text { kecelakaan kerja } \\
\text { Analisis :Anova, chi- } \\
\text { square, } t \text { independent } \\
\text { sample. }\end{array}$ & $\begin{array}{l}\text { Shifpagi dan sore emiliki rata-rata } \\
\text { jumlahkecelakaantertinggi. } \\
\text { pagiberhubungandengankecelakaankerja } \\
(\mathrm{p}=0,001) \text { dan shift sore }(\mathrm{p}=0,035)\end{array}$ \\
\hline
\end{tabular}




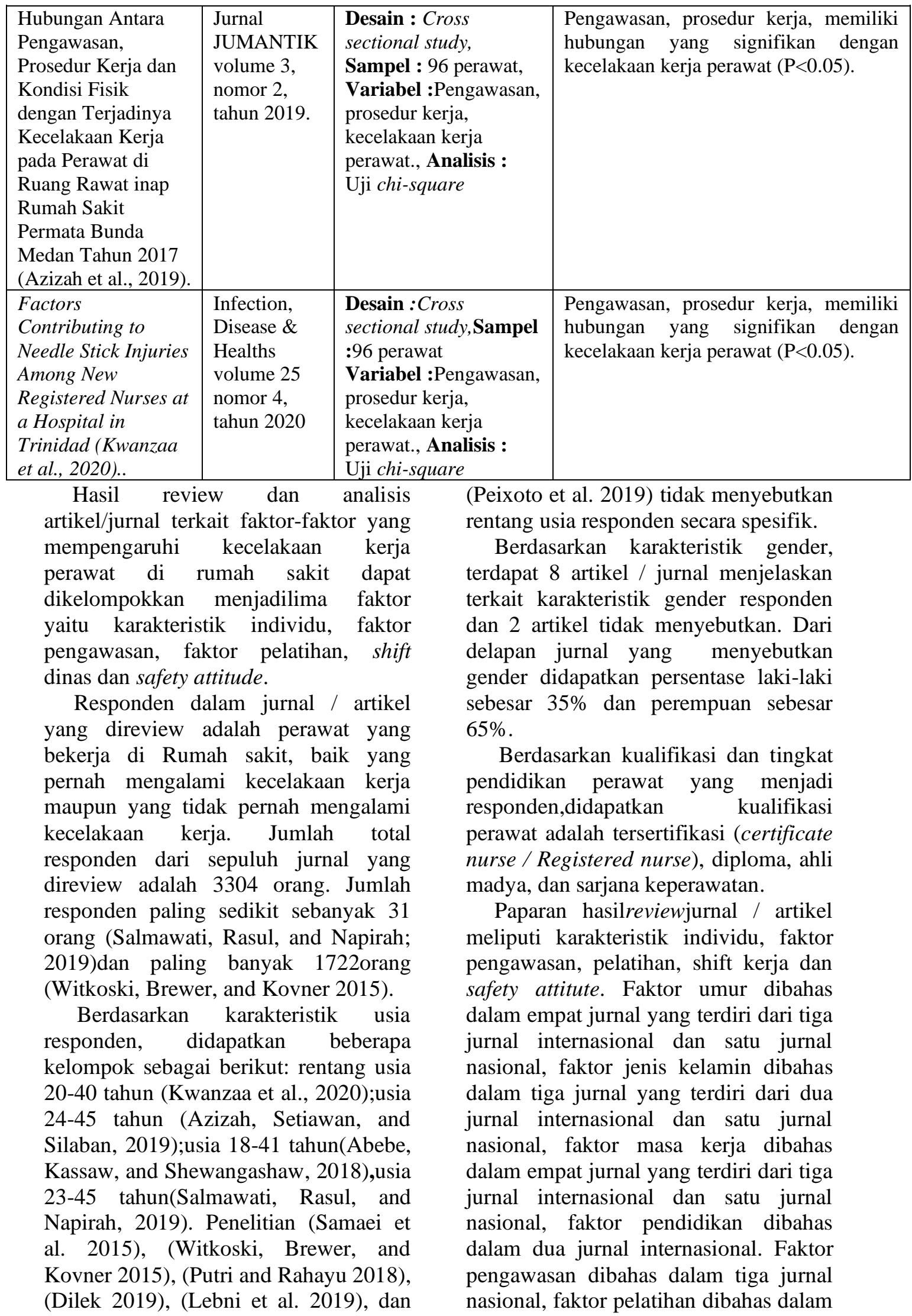


tiga jurnal, meliputi satu jurnal internasional dan dua jurnal nasional. Untuk faktor Shift dinas dibahas dalam empat jurnal internasional, dan faktor work area dibahas dalam dua jurnal internasional, dan faktor Safety Attitude dibahas dalam empat jurnal yeng terdiri dari dua jurnal internasional dan dua jurnal nasional.

Paparan hasil reviewartikel atau jurnal terkait faktor-faktor yang mempengaruhi kecelakaan kerja perawat di rumah sakit adalah sebagai berikut:

\section{1) Usia}

Empat jurnal membahas hubungan usia perawat dengan kecelakaan kerja. Dua studi menyatakan bahwa usia berhubungan dengan kecelakaan kerja perawat dan dua lainnya menyatakan tidak ada hubungan atau tidak ada pengaruh.

Dua studi pertama menjelaskan usia adalah faktor yang signifikan mempengaruhi kecelakaan kerja perawat di Rumah sakit dengan $p$ value $\quad 0,05$ (Lebni et al., 2019; Salmawati, Rasul, et al., 2019). Mayoritas perawat yang mengalami kecelakaan kerja berumur $\leq 30$ tahun dengan presentase masing-masing studi sebanyak $58,1 \%$ dan $78,4 \%$.Perawat berumur $\geq 30$ tahunmayoritas tidak mengalami kecelakaan kerja di Rumah sakit. Dalam dua studi ini menunjukkan bahwa kecelakaan kerja lebih banyak terjadi pada kelompok usia lebih muda.

Dua studi lainnya menunjukkan hasil bahwa usia tidak berpengaruh terhadap terjadinya kecelakaan kerja perawat di Rumah sakit dengan $p$ value $>0.05$ (Dilek 2019). Studi menunjukkan bahwa jumlah perawat yang mengalami kecelakaan kerja lebih sedikit. Satu studi didapatkan temuan bahwa perawat yang berusia $\leq 30$ tahun dan berumur $\geq 30$ tahun sama-sama tidak banyak mengalami kecelakaan kerja. Artinya jumlah perawat yang mengalami kecelakaan kerja pada kelompok usia kurang 30 tahun tidak jauh beda dengan kelompok usia yang lebih 30 tahun.

Hernawati (2008) menjelaskan bahwa pekerja berusia muda biasanya kurang berpengalaman dalam pekerjaannya sehingga berisiko terjadi kecelakaan kerja, akan tetapi golongan pekerja berusia tua juga mempunyai kecenderungan lebih tinggi mengalami kecelakaan kerja dibandingkan dengan golongan usia muda karena usia tua mengalami penurunan reaksi dan kegesitan. Hal ini sesuai dengan pendapat Wahyudi (2018) yang menjelaskan bahwa usia lebih 30 tahun akan mengalami penurunan kapasitas fisik, antara lain penurunan penglihatan, pendengaran dan kecepatan reaksi sehingga mereka berrisiko mengalami kecelakaan kerja lebih tinggi. Kelompok usia tua biasanya lebih hati-hati sehingga mereka bisa terhindar dari bahaya dan kecelakaan kerja.

Usia muda dan tua sama-sama mempunyai risiko untuk terjadinya kecelakaan kerja. Usia tidak berpengaruh terhadap terjadinya kecelakaan kerja perawat. Perawat dengan usia lebih muda dapat mengalami kecelakaan kerja karena kurang pengalaman, sedangkan perawat dengan usia lebih tua mengalami penurunan kondisi fisik yang berrisiko mengalami kecelakaan kerja.

\section{2) Jenis Kelamin}

Tiga jurnal membahas hubungan jenis kelamin dengan kecelakaan kerja perawat di rumah sakit. Dua studi menjelaskan bahwa jenis kelamin merupakan faktor yang mempengaruhi kecelakaan kerja perawat di Rumah sakit dengan $p$-value $<0.05$ (Salmawati, Rasul, et al., 2019; Lebni et al., 2019).Pada dua artikel tersebut dijelaskan bahwa persentase perawat yang mengalami kecelakaan kerja lebih banyak padaperawat laki-laki daripada perempuan. Satu studi 
menyatakan bahwa jenis kelamin tidak ada hubungan dengan kecelakaan kerja dengan pv > 0,05 (Dilek, 2019). Secara persentase, jumlah perawat laki-laki dan perempuan yang mengalami kecelakaan kerja hampir sama.

Tarwaka (2010) menjelaskan bahwa perempuan pada umumnya memiliki kekuatan fisik atau kekuatan otot lebih rendah daripada laki-laki, tetapi dalam hal tertentu perempuan lebih teliti dari laki-laki. Kekuatan fisik laki-laki dan ketelitian perempuan adalah kekuatan untuk mencapai hasil kerja yang baik.

Jenis kelamin bukan faktor yang mempengaruhi kecelakaan kerja perawat.Perawat berjenis kelamin perempuan maupun laki-laki samasama dapat mengalami kecelakaan kerja. Perempuan dapat mengalami kecelakaan kerja karena kondisi fisik yang lebih lemah, dan laki- laki dapat mengalami kecelakaan kerja karena kelelahan akibat beban kerja yang lebih berat dan kurangnya ketelitian. Kerjasama yang baik antara perawat laki-laki dan perempuan dalam melakukan pekerjaan perlu ditingkatkan dan memberikan tugas sesuai dengan kemampuan masingmasing agar dapat bekerja dengan baik dan mencegah terjadinya kecelakaan kerja.

\section{3) Masa Kerja}

Empat jurnal membahas hubungan masa kerja perawat dengan kecelakaan kerja. Satu studi menjelaskan bahwa masa kerja merupakan faktor yang mempengaruhi kecelakaan kerja perawat di Rumah Sakit dengan $p$ value $<0.05$ (Lebni et al., 2019). Studi ini menunjukkan bahwa kecelakaan kerja lebih tinggi pada kelompok perawat yang mempunyai masa kerja yang pendek.

Tiga studi lainnya menunjukkan hasil bahwa masa kerja tidak mempengaruhi kecelakaan kerja perawat di Rumah sakit dengan $p$ value> 0.05(Salmawati, Rasul, et al., 2019; Dilek, 2019). Hasil studi menunjukkan bahwa persentase perawat yang mengalami kecelakaan kerja adalah hampir sama antara yang mempunyai masa kerja pendek dan lama. Perawat yang mengalami kecelakaan kerja (51\%) dan yang tidak mengalami kecelakaan kerja (49\%). Studi lainnya menunjukkan bahwa persentase perawat $93 \%$ tidak mengalami kecelakaan kerja dialami perawat yang berumur lebih dari 30 tahun.Satu studilain menjelaskan bahwa perawat yang bekerja kurang dari 5 tahun maupun lebih dari 5 tahun tidak mengalami kecelakaan kerja. Perawat yang memiliki masa kerja pendek maupun panjang turut menyumbang kecelakaan kerja di Rumah sakit.

Suma'mur (2006) menjelaskan bahwa semakin lama pekerja bekerja di suatu tempat, maka semakin banyak dia telah terpapar bahaya yang ditimbulkan oleh lingkungan kerja tersebut. Pendapat ini berbeda dengan teori tiga faktor utama (Three Main Factor Theory) yang menjelaskan bahwa penyebab kecelakaan kerja salah satunya adalah masa kerja. Hal ini cukup beralasan karena masa kerja akan terkait dengan pengalaman dan keterampilankerja seseorang. Semakin lama seseorang bekerja maka semakin banyak pengalaman dan akan semakin meningkat keterampilannya. Masa kerja yang seseorang pasti memberikan sebuah pengalaman kerja, yang berpengaruh terhadap tingkat profesionalitas seseorang (Sabarguna and Sumarni, 2004).

Berdasarkan hasil studi dan teori, dapat dijelaskan bahwa masa kerja perawat bukan faktor yang dapat mempengaruhi terjadinya kecelakaan kerja. Masa kerja lama dapat membuat pekerja lebih banyak mendapatkan risiko bahaya yang dapat 
menimbulkan kecelakaan kerja. Masa kerja pendek dapat mengalami kecelakaan kerja karena minimnya pengalaman kerja.

\section{4) Pendidikan}

Dua jurnal membahas hubungan pendidikan perawat dengan kecelakaan kerja. Satu studi mengemukakan pendidikan merupakan faktor yang mempengaruhi kecelakaan kerja perawat di Rumah sakit dengan $p$ value $<0.05$ (Lebni et al., 2019). Hasil studi menjelaskan bahwa $83 \%$ dari jumlah kecelakaan kerja dialami perawat yang berpendidikan sarjana dibanding diploma 17\%. Dalam studi ini menjelaskan bahwa semakin tinggi pendidikan seseorang, semakin banyak yang akan terpapar dengan terjadinya kecelakaan kerja.

Satu studi lainnya menunjukkan hasil yang berbeda yaitu pendidikan tidak mempengaruhi kecelakaan kerja perawat di Rumah sakit dengan $p$ value $>0.05$. Studi ini menjelaskan bahwa Perawat dengan pendidikan diploma dan sarjana mempunyai persentase yang hampir sama untuk terjadi kecelakaan kerja.

Nursalam (2011)menjelaskan bahwa semakin tinggi tingkat pendidikan seseorang semakin banyak pula pengetahuan yang dimiliki. Hal ini berarti perawat dengan pendidikan tinggi akan menggunakannya pengetahuannya untuk bekerja dengan baik dan berkati-hati supaya tidak mengalami cidera. Hal ini berbeda dengan Arfida (2003) yang menjelaskan bahwa semakin tinggi pendidikan semakin tinggi produktivitas kerja, sehingga beban kerja yang diperoleh semakin besar. Beban kerja tinggi akan berrisko untuk terjadi kelelahan yang berpotensi untuk mengalami cidera.

Berdasarkan fakta dan teori yang digunakan, dapat dijelaskan bahwa tingkat pendidikan tidak mempengaruhi kecelakan kerja perawat. Perawat berpendidikan lebih tinggi, memiliki lebih banyak pengetahuan sehingga perawat dapat bekerja dengan baik dan lebih berhatihati. Akan tetapi, perawat berpendidikan tinggi juga bisa mengalami kecelakaan kerja karena beban pekerjaan yang lebih tinggi. Perawat berpendidikan sarjana maupun diploma memiliki peluang yang sama untuk mengalami kecelakaan kerja di Rumah sakit.

\section{5) Pengawasan}

Empat jurnal atau artikel membahas hubungan pengawasan dengan kecelakaan kerja. Tiga hasil studi menjelaskan bahwa pengawasan merupakan faktor yang mempengaruhi kecelakaan kerja perawat di Rumah sakit dengan $p$-value 0.05 (Kwanzaa et al., 2020; Azizah et al., 2019; Salmawati, Rasul, et al., 2019). Satu artikel menjelaskan bahwa pengawasan tidak berhubungan dengan terjadinya kecelakaan kerja dengan p-value> 0.05 (Putri \& Rahayu, 2018a).

Dua studi yang menemukan adanya pengaruh pengawasan dengan terjadinya kecelakaan kerja. Dijelaskan bahwa persentase kecelakaan kerja tertinggi (61\%), disebabkan oleh pengawasan yang kurang baik (84\%). Studi lain menjelaskan bahwa persentase kejadian kecelakaan kerja terendah $(17 \%)$ karena sebagian besar perawat mendapatkan pengawasan yang baik dengan persentase $88,9 \%$. Perawat yang kurang mendapatkan pengawasan, lebih sering mengalami kecelakaan kerja dibandingkan dengan perawat yang mendapat pengawasan baik.

Kepmenkes (2010) menjelaskan bahwa pengawasan memiliki andil dalam meminimalisir kejadian kecelakaan kerja. Hal ini sesuai dengan pendapat Utommi (2007)yang 
menjelaskan bahwa pengawasan adalah memastikan pekerja untuk bekerja secara baik dan tahu bagaimana melakukan pekerjaanya dengan benar. Pengawasan perawat di rumah sakit dilakukan sebelum melakukan pergantian shift, saat akan memberikan pelayanan kepada pasien, pengawasan kinerja berdasarkan SOP dan pengawasan terhadap posisi pada saat bekerja melayani pasien (Salmawati, Rasul, et al., 2019).

Pengawasan dapat mempengaruhi kecelakaan kerja perawat. Perawat yang mendapatkan pengawasan baik akan lebih memperhatikan prosedur kerja saat melakukan asuhan keperawatan. Sebaliknya perawat yang kurang mendapat pengawasan, akan kurang berhati-hati dan cenderung melakukan pekerjaan tidak sesuai dengan prosedur kerja. Jika pengasawan dilakukan secara rutin, maka akan meningkatkan ketaatan perawat melakukan pekerjaan sesuai standar prsedur operasional dan berhati-hati sehingga dapat meminimalkan terjadinya kecelakaan kerja.

\section{6) Pelatihan}

Tiga jurnal atau artikel membahas hubungan pelatihan dengan kecelakaan kerja. Hasil studi menjelaskan bahwa pelatihan merupakan faktor yang mempengaruhi terjadinya kecelakaan kerja perawat di Rumah sakit dengan $p$-value $<0.05$ (Abebe et al., 2018; Putri \& Rahayu, 2018a; Salmawati, Rasul, et al., 20). Hasil studi menunjukkan bahwa perawat yang mengalami kecelakaan kerja adalah perawat yang kurang pelatihan dibandingkan dengan yang mengikuti pelatihan dengan baik. Perawat yang kurang mengikuti pelatihan mempunyai presentase sebesar 78,8\% mengalami kecelakaan kerja, sedangkan perawat yang mendapatkan pelatihan dengan baik, mempunyai presentase lebih rendah yaitu $64,2 \%$ tidak mengalami kecelakaan kerja.

(Kepmenkes 2010), menjelaskan bahwa pelatihan merupakan salah satu faktor penting bagi perawat. Pelatihan terkait prosedur keselamatan kerja dapat meminimalisir terjadinya kecelakaan kerja. Kebutuhan pelatihan keselamatan dan kesehatan kerja di Rumah Sakit berbeda sesuai sifat bahaya, skala kegiatan dan kondisi petugas kesehatan (Ramli, 2010).

Rumah sakit merupakan lingkungan yang memiliki berbagai macam bahaya terutama bagi pekerja salah satunya perawat. Untuk mencegah terjadinya risiko kecelakaan kerja di lingkungan Rumah sakit, tindakan yang paling tepat adalah memberikan pelatihan, karena pelatihan dapat meningkatkan kemampuan dan kewaspadaan perawat untuk melakukan pencegahan dari bahaya yang mungkin terjadi.

7) Shift

Tiga jurnal membahas bahwa shift kerja adalah faktor yang mempengaruhi terjadinya kecelakaan kerja perawat di Rumah sakit dengan p-value $<0.05$ (Witkoski et al., 2015; Dilek, 2019; Peixoto et al., 2019), sedangkan Lebni et al. (2019) menjelaskan tidak ada hubungan antara shift kerja dengan kecelakaan kerja. Hasil studi didapatkan bahwa perawat yang bekerja shift sering mengalami kecelakaan kerja. Dua studi menjelaskan bahwa kejadian kecelakaan kerja lebih tinggi terjadi pada shift pagi $(37,8 \%)$, dan satu studi menjelaskan bahwa kecelakaaan kerja lebih tinggi terjadi saat shift malam hari.

Witkoski, Brewer, and Kovner (2015)menjelaskan bahwa mayoritas perawat yang bekerja pada shift malam adalah perawat baru yang masih perlu adaptasi dengan berbagai stressor, baik stressor fisik maupun 
psikologi saat bekerja. Mayoritas perawat baru bekerja selama 12 jam sehingga beban kerjanya cukup tinggi yang yang mengakibatkan terjadinya kelelahan. Selain itu dijelaskan bahwa pembagian shift kadang kurang adildengan menempatkan sebagian besar perawat baru untuk bekerja pada shift malam. Berbeda dengan Peixoto et al. (2019) yangmenjelaskan bahwa pagi adalah shift dengan waktu yang terlama sehingga perawat mendapat beban kerja lebih banyak, sedangkan sumberdaya perawat yang dibutuhkan kurang sehingga dapat menimbulkan risiko kecelakaan kerja yang lebih besar

Jahangiri et al. (2016) \&Martins et al. (2012) menjelaskan bahwa sebagai tenaga kerjadengan jumlah besar yang terlibat langsung dalam pelayanan di Rumah Sakit, perawat banyak terlibat dalam pengangkatan pasien, pemindahan pasien secara berulang serta menyuntikkan obat dan memasukkan infus yang sangat berpotensi untuk terjadinya cidera atau bahaya pada setiap tugasnya. Caruso (2014) menjelaskan bahwa kecelakaan kerja dapat terjadi terutama pada perawat yang bekerja shift dengan masalah seperti gangguan tidur, gangguan sistem pencernaan, dan depresi.

Marchelia (2014) efek negatif kerja shift dapat mempengaruhi kondisi pekerja dalam aspek fisiologis (circadian rhytms) maupun aspek psikologis, yaitu stress kerja yang dapat menyebabkan kelelahan. Dampak lain kerja shift ditinjau dari aspek kinerja, dapat diketahui dari tingkat kesalahan, ketelitian, dan tingkat kecelakaan yang berbeda-beda setiap shift. Kerja shift juga dapat berdampak padaaspek domestik dan sosial antara lain konflik keluarga dan sosialisasi berkurang.

Berdasarkan hasil studi dapat dijelaskan bahwa shift kerja perawat dapat mempengaruhi kecelakaan kerja. Sumber daya perawat yang kurang mengakibatkan bebat kerja lebih berat, ditambah dengan pembagian waktu shift kurang adil, dapat mengakibatkan kesalahan kerja sehingga dapat terjadi kecelakaan kerja.

\section{8) Work Area}

Jurnal yang membahas hubungan work area perawat bekerja dengan kecelakaan kerjadilakukan oleh Abebe et al., (2018). Hasil studi menjelaskan bahwa work area merupakan faktor yang berpengaruh terhadap terjadinya kecelakaan kerja perawat di Rumah sakit dengan $p$ value $<0.05$. Perawat yang bekerja di Unit Gawat Darurat sebelas kali berisiko mengalami kecelakaan kerja dibandingkan perawat yang bekerja di rawat jalan. Perawat yang bekerja di Rawat inap sepuluh kali berisiko mengalami kecelakaan kerja dibanding perawat yang bekerja di rawat jalan.

Studi lain menjelaskan bahwa works area tidak ada hubungan dengan terjadinya kecelakaan kerja. Hal ini sesuai dengan Kepmenkes (2010) yang menjelaskan bahwa tiap area di Rumah sakit memiliki tingkat bahaya berbeda sehingga perawat yang bekerja di area yang berbeda memiliki risiko kecelakan kerja yang berbeda pula. Upaya yang dapat dilakukan untuk mengurangi kecelakaan kerja pada perawat adalah dengan melakukan kredensial dan menambah jumlah perawat untuk memenuhi standar minimal jumlah perawat sesuai dengan pelayanan yang diberikan.

\section{9) Safety Attitude}

Faktor safety attitude mempengaruhi terjadinya kecelakaan kerja perawat di Rumah sakit dengan p-value 0.05 (Samaei et al., 2015; Putri \& Rahayu, 2018a). Hasil studi menjelaskan bahwa jumlah perawat yang tidak mengalami kecelakaan kerja, mayoritas adalah perawat 
dengan safety attitude baik (93,7\%). Perawat yang memiliki safety attitude kurang baik dalam melakukan pekerjaan lebih sering mengalami kecelakaan kerja, dibanding perawat yang memiliki safety attitude baik.

Hasil studi tersebut sesuai dengan temuanMaria, Wiyono, and Candrawati (2015) yang menjelaskan bahwa melakukan pekerjaan tanpa menerapkan prosedur kesehatan keselamatan kerjaadalah tindakan yang membahayakan pekerja itu sendiri maupun orang lain dan dapat menyebabkan terjadinya kecelakaan kerja. Safety attitute yang tidak baik dan dapat menyebabkan terjadinya kecelakaan kerja antara lain: tidak memakai alat proteksi diri (APD), tidak mengikuti prosedur kerja, tidak mengikuti peraturan keselamatan kerja dan bekerja tidak hati-hati. Penelitian lain juga menjelaskan bahwa ada hubungan signifikan antara sikap keselamatan pekerja dan perilaku aman mereka terhadap kecelakaan dan cidera (Hong 2015; Zakari 2011). Mousavi et al. (2015)juga menjelaskan bahwa Safety attitude (sikap) merupakan faktor utama mencegah kecelakaan kerja pada perawat.

Safety attitude saat bekerja adalah hal yang penting bagi perawat dalam bekerja untuk mencegah terjadinya kecelakaan kerja, antara lain dengan cara bekerja sesuai prosedur dan menggunakan APD.

\section{KESIMPULAN}

1) Faktor pengawasan mempengaruhi kecelakaan kerja perawat di rumah sakit. Pengawasan yang baik dapat meminimalisir terjadinya kecelakaan kerja perawat, dengan pengawasan yang baik perawat lebih memperhatikan prosedur kerja, sebaliknya perawat yang kurang mendapat pengawasan, akan kurang berhati-hati dan cenderung melakukan pekerjaan tidak sesuai dengan prosedur kerja.

2) Faktor pelatihan mempengaruhi kecelakaan kerja perawat di rumah sakit. Pelatihan dapat meningkatkan kompetensi dan ketaatan dalam menjaga keselamatan sehingga dapat meminimalisir terjadinya kecelakaan kerja.

3) Faktor shift mempengaruhi kecelakaan kerja perawat di rumah sakit. Perawat yang bekerja shift pagi dan malam lebih sering mengalami kecelakaan kerja karena rentang waktu kerja yang lama dan kelelahan sehingga tidak fokus dalam bekerja.

4) Faktor safety attitude mempengaruhi kecelakaan kerja perawat di rumah sakit. Safety atiitude yang baik dapat meminimalisir perawat mengalami kecelakaan kerja.Melakukan prosedur kerja dan prosedur keselamatan secara tepat dalam melakukan pekerjaan, dapat terhindar dari adanya kesalahan saat melakukan pekerjaan yang bisa menimbulkan kecelakaan kerja.

\section{SARAN}

1) Pengawasan melalui supervisi terhadap kinerja perawat perlu dilakukan secara rutin dan terjadwal agar perawat selalu dapat mengontrol diri untuk patuh terhadap prosedur kerja dan berhatihati dalammelakukan pekerjaan.

2) Peningkatan pengetahuan dan keterampilan secara berkala melalui pelatihan terkait safety kerja di rumah sakit perlu dilakukan bagi semua perawat dan tenaga kesehatan lainnya, karena pelatihan dapat meningkatkan kompetensi dan ketaatan dalam menjaga keselamatan sehingga dapat meningkatkan kewaspadaan dan mencegah kecelakaan kerja.

3) Perawat yang bekerja shift perlu istirahat yang cukup, dan didukung oleh jumlah tenaga yang memadai sehingga dapat mengurangi beban kerja perawat sehingga dapat meminimalkan faktor kelelahan akibat 
waktu kerja yang panjang.

4) Safety attitude perlu terus menerus di tingkatkan baik oleh perawat maupun tenaga kesehatan lain yang bekerja di rumah sakit. Safety attitude dapat mengontrol perilaku perawat untuk patuh melakukan prosedur kerja dan prosedur keselamatan sehinga dapat mencegah kesalahan saat melakukan pekerjaan yang dapat menimbulkan kecelakaan kerja.

\section{REFERENSI}

Abebe, Ayele Mamo, Mesfin Wudu Kassaw, and Nathan Estifanos Shewangashaw. 2018. "Prevalence of Needle - Stick and Sharp Object Injuries and Its Associated Factors among Staff Nurses in Dessie Referral Hospital." BMC Research Notes: $1-6$. https://doi.org/10.1186/s13104-0183930-4.

Arfida. 2003. Ekonomi Sumber Daya Manusia. Jakarta: Ghalia indonesia.

Aslam, Imran, Scott A Davis, Steven R Feldman, and Willis E Martin. 2015. "A Review of Patient Lifting Interventions to Reduce Health Care Worker Injuries." 63(6): 267-75.

Azizah, Nur, Setiawan, and Gerry Silaban. 2019. "Hubungan Antara Pengawasan, Prosedur Kerja Dan Kondisi Fisik Dengan Terjadinya Kecelakaan Kerja Pada Perawat Di Ruang Rawat Inap Rumah Sakit Permata Bunda Medan Tahun 2017." 3(2): 125-34.

Bae, Sung-heui, and Donna Fabry. 2014. "Assessing the Relationships between Nurse Work Hours / Overtime and Nurse and Patient Outcomes: Systematic Literature Review." Nursing Outlook 62(2): 138-56. http://dx.doi.org/10.1016/j.outlook.20 13.10.009.
Caruso, Claire C. 2015. "Negative Impacts of Shiftwork and Long Work Hours Claire." 39(1): 16-25.

Caruso, Claire C. 2014. "Negative Impacts of Shiftwork and Long Work Hours." : 1-9.

Davas, A, M Türk, and M Yüksek. 2016. "The Relationship between Working Conditions and Work Accidents: A Hospital Example.” 60-61: 67-75.

Denney, Andrew S, and Richard Tewksbury. 2015. "How to Write a Literature Review." (August).

Dilek, Filiz. 2019. "Factors Affecting The Occupational Accident Rates Among Nurses." : 1-8.

Hernawati, Eva. 2008. "Faktor-Faktor yang Berhubungan dengan Kejadian Kecelakaan Kerja Bedasarkan Karakteristik pekerja dan Unit Kerja di Area Pertambangan PT. ANTAM TBK UBPE Pongkor Bogor Jawa Barat Tahun 2006-2007." Universitas Islam Syarif Hidayatullah.

Hong, Sung Jung. 2015. "Perception of Safety Attitude and Priority and Progress of Safe Practices of Nurses in Emergency Room." 8(11): 125-38.

Jahangiri, Mehdi et al. 2016. "Needle Stick Injuries and Their Related Safety Measures among Nurses in a University Hospital , Shiraz , Iran.” Safety and Health at Work 7(1): 7277.

http://dx.doi.org/10.1016/j.shaw.2015 .07.006.

Kepmenkes. 2010. Standar Kesehatan dan Keselamatan Kerja di Rumah Sakit.

Kwanzaa, Caimete Smith et al. 2020. "Factors Contributing to Needle Stick Injuries Among New Registered Nurses at a Hospital in Trinidad." Infection, Disease \& Health (xxxx). https://doi.org/10.1016/j.idh.2020.06. 003.

Lebni, Javad Yoosefi et al. 2019. "Factors 
Affecting Occupational Hazards among Operating Room Personnel at Hospitals Affiliatedin in Western Iran : A Cross-Sectional Study."

Marbun, Natalia. 2020. "Factors Affecting the Occupational Accident Rates among Nurses.” (July): 0-8.

Marchelia, Venny. 2014. "Stres Kerja Ditinjau Dari Shift Kerja Pada Karyawan.” 02(01): 130-43.

Maria, Silvia, Joko Wiyono, and Erlisa Candrawati. 2015. "Kejadian Kecelakaan Kerja Perawat Bedasarkan Tindakan Tidak Aman." 3(2): 9-17.

Martins, Artur et al. 2012. "Age and Years in Practice as Factors Associated with Needlestick and Sharps Injuries among Health Care Workers in a Portuguese Hospital." Accident Analysis and Prevention 47: 11-15. http://dx.doi.org/10.1016/j.aap.2012. 01.011 .

Mccaughey, Deirdre et al. 2016. "Antecedents to Workplace Injury in the Health Care Industry: A Synthesis of The Literature." 41(1): $42-55$.

Mousavi, F et al. 2015. “'.Survey of Patient Safety Climate from Nursing Views." Intl Res J Appl Basic Sci. 9(7): 118693.

Nayak, Sandeep et al. 2016. "WorkRelated Injuries and Stress Level in Nursing Professional." 5(08): 169397.

Nazirah, Riska, and Yuswardi. 2017. "Perilaku Perawat dalam Penerapan ManajemenKesehatan dan Keselamatan Kerja (K3) DI ACEH." VIII(3).

Nursalam. 2011. Pendidikan Dalam Keperawatan. Jakarta: Salemba Medika.

Nursalam. 2020. Penulisan Literature Review Dan Systematic Review Pada
Pendidikan Keperawatan/Kesehatan. Surabaya: Fakultas Keperawatan Universitas Airlangga.

OSHA. 2015. "Occupational Safety and Health Administration." United States Department of Labor. https://www.osha.gov/dep/enforceme nt/inpatient_insp_06252015.html.

Peixoto, Silva, Jeferson Santos Araújo, Mônica Custódia, and Abreu Pamplona. 2019. "Factors Related to Occupational Accidents Among Nursing Professionals from a Public Hospital in Northern Brazil between the Years 2009 to 2016." 17(4): 52129.

Pitoyo, Joko, Rudi Hamarno, Titis Elija, and RSUD Dr. Iskak Tulungagung. 2017. "Kepatuhan Perawat Menerapkan Pedoman Keselamatan Kerja Dan Kejadian Cidera Pada Perawat Instrumen Di Instalasi Bedah Sentral." 6(2): 65-70.

Putri, Sentya, and Endang Purnawati Rahayu. 2018. "Pelaksanaan Keselamatan Dan Kesehatan Kerja Terhadap Kejadian Kecelakaan Kerja Perawat Rumah Sakit.” 3(2): 271-77.

Sabarguna, B. S., and Sumarni. 2004. Sumber Daya Manusia Rumah Sakit. Yogyakarta: Konsorsium Rumah Sakit Islam Jateng.

Salmawati, Lusia, Muh. Rasul, and Muh. Ryman Napirah. 2019. "Faktor Yang Berhubungan Dengan Kejadian Kecelakaan Kerja Pada Perawat Di Ruang IGD RSU Anutapura Kota Palu." 10: 104-12.

Samaei, Seyed Ehsan et al. 2015. "Safety Attitudes among Nurses and Its Relation with Occupational Accidents: A Questionnaire Based Survey." : 177-86.

Suma'mur. 2006. Higiene Perusahan Dan Kesehatan Kerja. PT. Toko Gunung Agung.LenePerusahan Dan Kesehatan Kerja. Jakarta: PT. Toko 
Gunung Agung.

Suma'mur. 2013. Higiene Perusahaan Dan Kesehatan Kerja (HIPERKES). Jakarta: CV. Sagung Seto.

Tarwaka. 2010. Ergonomi Industri. Surakarta: Harapan Press.

Utommi, Sendy. 2007. "Gambaran Tingkat Kepatuhan Pekerja Dalam Mengikuti Prosedur Operasi Pada Pekerja Operator Dump Truck Di PT. Kaltim Primacoal Tahun 2007." Indonesia University.

Wahyudi, Agung. 2018. "Keselamatan Dan Kesehatan Kerja (K3): Investigasi Kecelakaan Kerja." Asosiasi Tenaga Teknik Indonesia (ASTTI), LP2K TTI Seri K3.
http://astti.or.id/sites/default/files/Seri K3 - BAB 5 - Kecelakaan Kerja.pdf.

Witkoski, Amy, Carol S Brewer, and Christine T Kovner. 2015. "International Journal of Nursing Studies Scheduling and Shift Work Characteristics Associated with Risk for Occupational Injury in Newly Licensed Registered Nurses: An Observational Study." International Journal of Nursing Studies. http://dx.doi.org/10.1016/j.ijnurstu.20 15.06.011.

Zakari, Nazik M A. 2011. "Attitude of Academic Ambulatory Nurses toward Patient Safety Culture in Saudi Arabia." 8(3): 230-37. 